\title{
Novel Concepts in Male Infertility
}

\author{
Sandro C. Esteves, Ashok Agarwal \\ ANDROFERT (SCE), Center for Male Reproduction, Campinas, Sao Paulo, Brazil and Center for Reproductive Medicine \\ (AA), Cleveland Clinic, Cleveland, Ohio, USA
}

\begin{abstract}
Extraordinary advances have been achieved in the field of male infertility in the last decades. There are new concepts in sperm physiology and several modern tools for the assessment of spermatogenesis kinetics in vivo. New tests using molecular biology and DNA damage assays allow the clinician to correctly diagnose men so far classified as having idiopathic male infertility. In the field of treatment, microsurgery has increased success rates either for reconstruction of the reproductive tract or the retrieval of spermatozoa for assisted conception. Emerging evidence suggests that life-style and environmental conditions are of utmost importance in male fertility and subfertility. This review discusses several concepts that have changed over the last years, such as the duration of the spermatogenic cycle in humans, Y-chromosome infertility, the reproductive potential of non-mosaic Klinefelter syndrome men, the impact of paternal age and sperm DNA in male infertility, the role of antioxidants in the treatment of infertile men, the predictive factors and techniques for sperm retrieval in non-obstructive azoospermia, and the microsurgical treatment of clinical varicoceles. Whenever possible, levels of evidence are provided as suggested by the Oxford Center of Evidence-based Medicine.
\end{abstract}

Key words: male infertility, semen, azoospermia, varicocele, assisted reproductive techniques, evidence-based medicine Int Braz J Urol. 2011; 37: 5-15

\section{INTRODUCTION}

Approximately $8 \%$ of men in reproductive age seek medical assistance for fertility-related problems. Of these, $1-10 \%$ carries conditions that compromise the reproductive potential; varicocele accounts for $35 \%$ of the cases (1). The urologist's role in this field cannot be underestimated. He/she is trained to diagnose, counsel, provide medical or surgical treatment whenever possible and correctly refer the male patient for assisted conception. By integrating the reproductive team, the urologist is responsible for the above-cited tasks and to perform surgical sperm retrieval.

The urologist should also be aware of the recently published evidence that have challenged several established concepts in male infertility. This review discusses the main concepts that have changed over the previous years and provides the levels of evidence, whenever possible, as suggested by the Oxford Center of Evidence-based Medicine (2).

\section{DURATION OF THE SPERMATOGENIC CYCLE}

Misell et al. (2006) have shown for the first time that the time from initiation of spermatogenesis to appearance in the ejaculate is approximately 64 days, significantly shorter than the previously suspected 70 to 80 -day period (3). Men with normal sperm concentrations ingested ${ }^{2} \mathrm{H}_{2} \mathrm{O}$ daily and semen samples were collected every 2 weeks for up to 90 days. ${ }^{2} \mathrm{H}_{2} \mathrm{O}$ label incorporation into sperm DNA was 
quantified by gas chromatography/mass spectrometry, allowing calculation of the percent of new cells. The overall mean time to detection of labeled sperm in the ejaculate was $64 \pm 8$ days (range 42-76). They also observed biological variability, thus contradicting the current belief that spermatogenesis duration is fixed among individuals. All subjects achieved greater than $70 \%$ new sperm in the ejaculate by day 90 , but plateau labeling was not attained in most, suggesting rapid washout of old sperm in the epididymal reservoir (4). Their data also suggested that in normal men, sperm released from the seminiferous epithelium enter in the epididymis in a coordinated manner with little mixing of old and new sperm before subsequent ejaculation. This is also a new concept, because it had been suggested that because of mixing, in any segment of the epididymal duct, the population of sperm would be heterogeneous in age and biological status.

\section{Y-CHROMOSOME INFERTILITY}

Y-chromosome infertility is characterized by azoospermia or severe to moderate oligozoospermia, although rare cases of mild oligozoospermia $\left(5-20 \times 10^{6} \mathrm{sperm} / \mathrm{mL}\right.$ semen $)$ may occur. Men with Y-chromosome infertility have no obvious symptoms, but physical examination may reveal small testes and/or cryptorchidism or varicoceles. One report suggested that a specific deletion in the AZFc region (gr/gr) might increase the susceptibility to testicular cancer (5). The prevalence of Y-chromosome microdeletions is estimated to be about 1:2000 to 1:3000 males; the frequency in males with azoospermia or severe oligozoospermia is about $5 \%-12 \%$, although a marked difference is reported in different world regions (6).

Clinically available molecular testing may reveal microdeletions in the long arm of the Y-chromosome The diagnosis of Y-chromosome microdeletions consists of a series of polymerase chain reaction amplifications within relatively broad regions of the Y-chromosome. Originally, three regions were defined: AZFa, AZFb and AZFc (azoospermia factor), which map on the long arm (Yq) from the centromere to the telomere (7). A fourth region, named AZFd, located between $\mathrm{AZFb}$ and $\mathrm{AZFc}$ was also reported.
The relative frequency of individual microdeletions are $60 \%, 5 \%$ and $16 \%$ for AZFc, AZFa and AZFb regions, but combined deletions occur in about $15 \%$ of cases (8). Because deletions tend to occur between large palindromic repeats, Repping et al. (2002) proposed a more appropriate nomenclature using the name of the flanking repeats for the types of recurrent deletions (7) (Figure-1).

Pregnancies can be achieved by in vitro fertilization (IVF) using intracytoplasmic sperm injection (ICSI) in males with Y-chromosome infertility exhibiting oligozoospermia or azoospermia with retrievable testicular sperm $(9,10)$. The presence of a deletion has no apparent negative effect on fertilization or pregnancy and it does not increase the risk for birth defects in children conceived via assisted reproduction technology (ART) (11) (Level $\mathrm{C}$ evidence). The presence of sperm in men with Y-chromosome microdeletions varies with the type of deletion. Testicular phenotypes associated with microdeletions in the AZFa region are the most severe and include Sertoli cell-only (SCO) pattern on testis histology (10). Testicular phenotypes associated with microdeletions restricted to AZFc ranged from azoospermia to moderate oligozoospermia whereas $\mathrm{AZFb}$ microdeletions are often associated to azoospermia. Individuals with AZFd microdeletions manifest the broadest range of testicular phenotypes. In partial and complete AZFc deletion azoospermic patients, sperm can be found in the testis in $70 \%$ of the cases. In contrast, the chance of finding sperm in azoospermic men with complete AZFa or AZFb deletions is unlikely (11) (Level $\mathrm{C}$ evidence). Large deletions involving multiple AZF regions generally present with testicular phenotypes similar to those restricted to $\mathrm{AZFa}$ (6).

Y-chromosome infertility is inherited in a Y-linked manner. Deletions are usually de novo and therefore not present in the father of the proband. Rarely, within a family, the same deletion of the Y chromosome can cause infertility in some males but not in others; hence, some fertile males with deletion of the AZF regions have fathered sons who are infertile (12). In pregnancies achieved from males with infertility caused by deletion of the AZF regions using ICSI, male offspring have the same deletion as their father. 


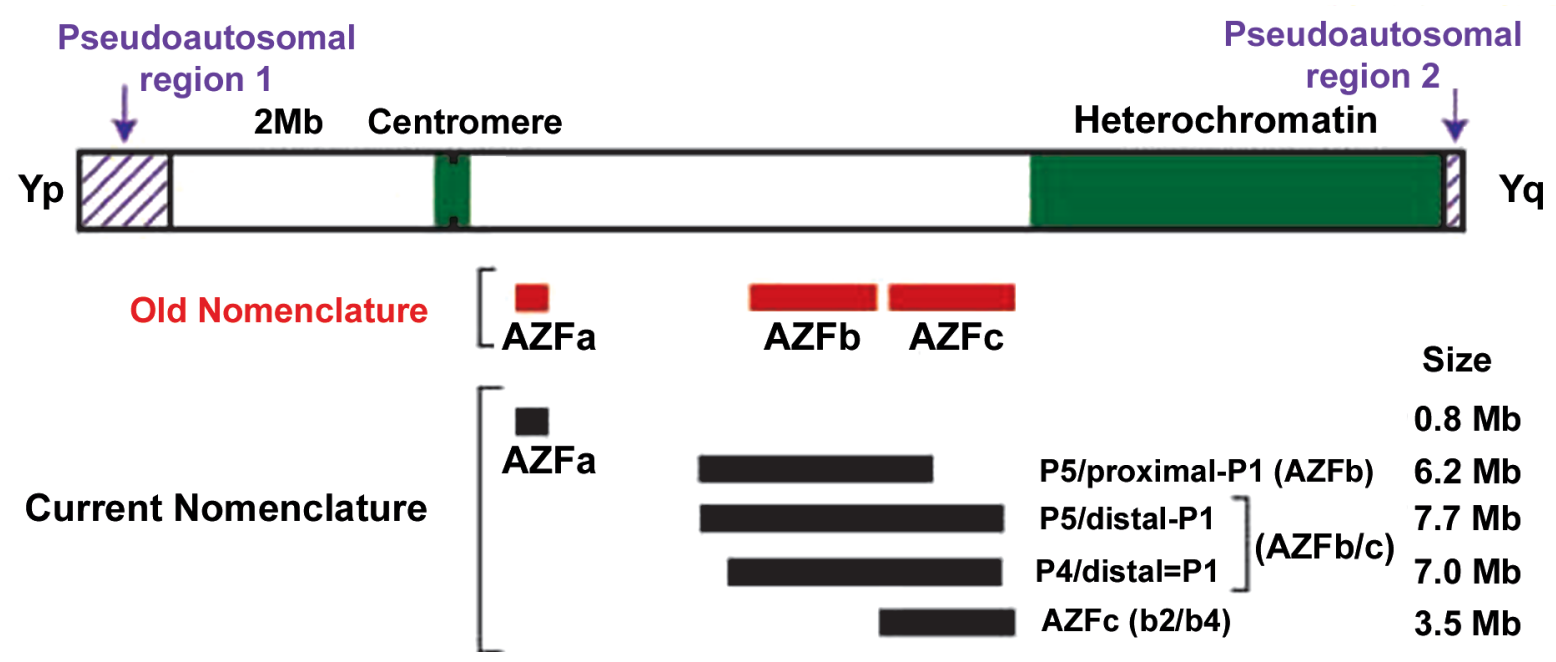

Figure 1 - Illustration of the Y chromosome in humans and the regions involved in fertility and infertility. Interstitial or terminal deletions that include AZFa, often mediated by recombination between the HERV15yq1-HERV15yq2 repeats, usually produce the severe phenotype of Sertoli-cell-only syndrome. Interstitial or terminal deletions that include AZFb and/or AZFb+c (hereafter designated $A Z F b / c)$ are mediated by recombination between palindromic repeats, either P5/proxP1, P5/distP1, or P4/distP1. These deletions usually result in azoospermia. Interstitial or terminal deletions that include AZFc only are mediated by recombination between the b2/b4 palindromic repeats and result in a variable phenotype, ranging from azoospermia and SCOS to severe or mild oligozoospermia. This type of deletion can occasionally be associated with normal fertility in younger males, with the phenotype worsening with age. Such individuals should consider cryopreservation of ejaculated sperm in early adulthood. Two partial deletions of AZFc, called b1/b3 and $\mathrm{gr} / \mathrm{gr}$, are considered polymorphisms. (Adapted from Am J Hum Genet. 71(4), Repping S et al., Recombination between Palindromes P5 and P1 on the Human Y Chromosome Causes Massive Deletions and Spermatogenic Failure, pages: 906-22, Copyright 2002, with permission from Elsevier).

\section{REPRODUCTIVE POTENTIAL OF NON- MOSAIC KLINEFELTER SYNDROME MEN}

The frequency of Klinefelter syndrome (KS), a specific chromosomal abnormality $(47, \mathrm{XXY})$, is $0.2 \%$ of male newborns and $11 \%$ of azoospermic men (13). The sterility of KS is due to the high prevalence of azoospermia presentin $92 \%$ of KS men; the remainder have a median of 0.1 million sperm $/ \mathrm{mL}$. Nevertheless, sperm are found in $50 \%$ of cases on testicular exploration and pregnancy rates by ICSI range from $30 \%$ to $50 \%$ (13). None of the clinical parameters are predictive of success in sperm retrieval.

KS men fathered more than 60 children worldwide; $~ 50$ had karyotype analysis all being normal $(13,14)$. Sciurano et al. (2009) have shown that seminiferous tubuli with germ cells represents only a minor fraction of all tubuli in men with nonmosaic KS. Using fluorescence in situ hybridization (FISH), they showed that meiotic spermatocytes are euploid, and thus can form normal, haploid gametes. Sertoli cells showed two marks for the X chromosome, meaning that they were 47, XXY (15). These new findings may explain the high rate of normal children born after testicular sperm extraction plus ICSI when applied to KS.

Sperm retrieval rate appeared to be lower $(20 \%)$ in KS men who previously received exogenous androgens (13). Such treatment may suppress the hypothalamic-pituitary-testis axis, impairing FSH secretion and decreasing intratesticular androgen levels that could impair spermatogenesis. Ramasamy et al. (2009) showed that other medications leading to endogenous testosterone increase seem to benefit KS men. In their study, KS men with either normal or low baseline testosterone but who respond to medical therapy (aromatase inhibitors, clomiphene or human 
chorionic gonadotropin) had a better chance of sperm retrieval (77\% vs. 55\%) (16) (Level C evidence).

\section{PATERNAL AGE AND INFERTILITY}

There is a general belief that the fertility potential of older man is fairly well preserved. However, recent evidence support the concept that advanced paternal age is associated with an increase in sperm chromosomal aneuploidy $(17,18)$. The risk for a father over 40 years-old to have a child with an autosomal dominant mutation equals the risk of Down syndrome for a child whose mother is $35-40$ years-old. Also, fathers over the age of 40 had a $20 \%$ greater chance of having a baby born with a serious birth defect (18). Moskovtsky et al. (2006) demonstrated that the rate of sperm with fragmented DNA doubled in men 45 years and older compared to those less than 30 years old (19) (Level B evidence). Siddighi et al. (2007) showed increased necrosis, DNA damage and apoptosis while rapid progression and total motility declined with advancing male age beginning as early as age 35 (20). Plastira et al. (2007) demonstrated that increased age in infertile patients was associated with an increase in sperm DNA fragmentation and poor chromatin packaging, as well as with a decline in semen volume, sperm morphology and motility (21) (Level $\mathrm{C}$ evidence). The current findings may help to define better cut-off age limits for donor sperm banking guidelines.

\section{SPERM DNA INTEGRITY AND FERTILITY}

In clinical practice, traditional semen analysis maintains its central role in the assessment of male fertility potential. However, in several cases abnormalities in the male genome characterized by damaged sperm DNA may be indicative of subfertility regardless of routine semen parameters (22).

Assays to evaluate sperm chromatin/DNA integrity can be divided in three groups (23): a) sperm chromatin structural probes using nuclear dyes (e.g. microscopic acridine orange test [AOT], sperm chromatin structural assay [SCSA], aniline blue test
[AB], chromomycin- A3 [CMA3] and toluidine blue $[\mathrm{TB}], \mathrm{b})$ tests for direct assessment of sperm DNA fragmentation (e.g. terminal deoxynucleotidyl transferase mediated dUTP nick end labeling assay [TUNEL] and single-cell gel electrophoresis assay [COMET], and c) sperm nuclear matrix assays (e.g. sperm chromatin dispersion test). Sperm DNA damage levels are significantly different between fertile and infertile men. The probability of fertilization in vivo and by intrauterine insemination (IUI) seems to be close to zero if the proportion of sperm cells with DNA damage exceeds 30\% (DFI) as detected by SCSA (24) (Level B evidence). Semen samples containing $>12 \%$ sperm with fragmented DNA (TUNEL) resulted in no pregnancies in IUI (25). Sperm DNA damage is negatively correlated with embryo quality and blastocyst formation in IVF cycles and with fertilization rates in both IVF and ICSI (26). However, successful pregnancies in IVF/ICSI can be obtained using semen samples with high proportion of DNA damage. Bungum et al. (2004) demonstrated that higher clinical pregnancy rates (52.9\% vs. $22.2 \%)$ and delivery rates $(47.1 \%$ vs. $22.2 \%)$ were obtained after ICSI as compared to IVF when semen samples with high levels of sperm DNA damage were used, as previously suggested (27) (Level B evidence). Despite these data, a recent meta-analysis failed to support the concept that DNA integrity testing was more predictive for IVF than ICSI, and even that such testing is predictive of pregnancy outcome either in IVF or ICSI (28) (Level A evidence).

The proportion of sperm with DNA damage was shown to be higher in men from couples with recurrent pregnancy loss compared to the general population or fertile donors (29). It is suggested that $39 \%$ of miscarriages could be predicted using a combination of sperm DNA integrity assays (30) (Level C evidence). Aitken and Krausz (2001) proposed that sperm DNA damage is promutagenic; mutations can occur after fertilization as the oocyte attempts to repair DNA damage prior to the initiation of the first cleavage. Mutations occurring at this point will be fixed in the germline and may be responsible for the induction of infertility, childhood cancer in the offspring and higher risk of imprinting diseases (31). So far, follow-up of children born after ICSI compared with children born after conventional IVF have not 
been conclusive regarding the risks of congenital malformations, imprinting diseases and health problems in general (32).

Existing data justify the introduction of sperm DNA damage assessment into the male infertility workup, but current evidence are not strong enough to provide a clinical indication for routine use in infertility evaluation $(23,28)$ (Level A-B evidence). Sperm DNA damage testing may be indicated in un- explained or idiopathic infertility, when a traditional semen analysis is normal and no evident female reproductive system pathologies can be revealed, and in selected cases of recurrent miscarriage. The ART method of choice can be recommended based on sperm DNA damage results and testicular instead of ejaculated sperm may be used for ICSI attempting to optimize reproductive outcomes in selected cases. Whether sperm DNA damage can be treated, allow-

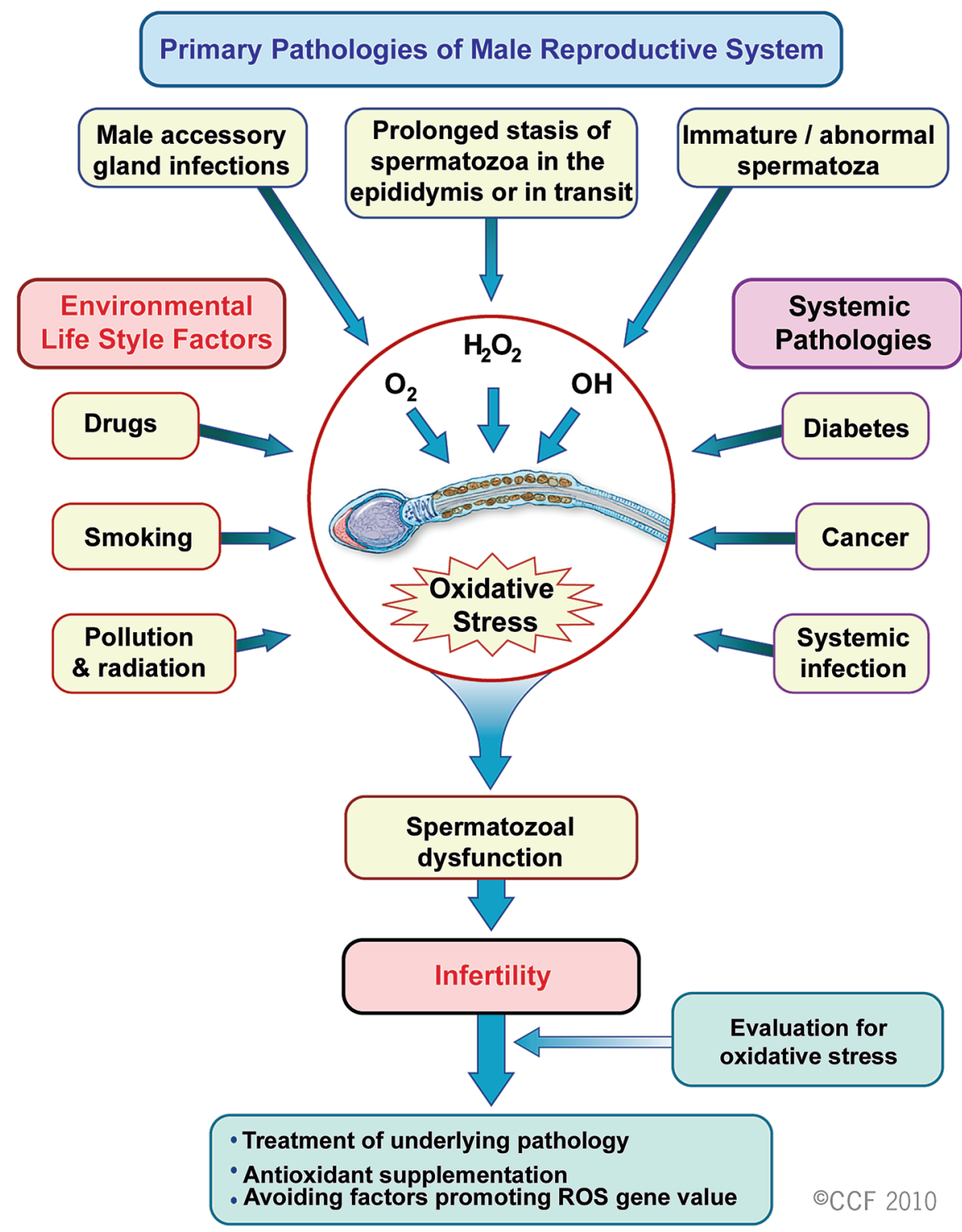

Figure 2-Relationship of the primary pathologies of the male reproductive system, oxidative stress and infertility. 
ing these couples to switch from ICSI to IVF/IUI or even achieve a pregnancy in a natural way, remains to be elucidated (33).

\section{OXIDATIVE STRESS AND INFERTILITY}

Oxidative stress (OS) is induced by reactive oxygen species (ROS) (33). Normal levels of ROS are required for sperm physiology, but excessive levels of ROS can negatively affect sperm quality (Figure 2). The OS-induced sperm damage has been suggested to be a significant contributing factor in $30-80 \%$ of all cases of male infertility (34). The generation of ROS can be exacerbated by environmental, infectious, and lifestyle etiologies (35-37). For example, exposure to cigarette smoke generates high levels of OS, directly increasing seminal leukocyte concentrations and seminal ROS generation, and decreasing seminal levels of the antioxidant enzyme superoxide dismutase (SOD). Smoking decreases concentrations of the seminal plasma antioxidants thereby reducing the oxidant scavenging capacity of the spermatozoa and seminal fluid (38).

Oxidative stress can be measured using direct and indirect assays. Direct assays measure the net oxidative sum of the balance between ROS production and intra- and extracellular antioxidants that scavenge ROS. The most used direct assay measures malondialdehyde, one of the final products of sperm cell membrane lipid peroxidation. Quantification of sperm DNA damage has also been used as a direct assay of intracellular ROS-induced oxidant injury (39). The most common indirect method for seminal ROS measurement is via chemiluminescence. Luminol or lucigen probes can be used for quantification of redox activities of spermatozoa; they have well established reported ranges for fertile and infertile populations thus bringing clinical relevance to its use (39).

Recent reports have focused on the therapeutic management of OS in male infertility. Varicocele increase OS levels in the testes as well as semen, and varicocelectomy may decrease seminal OS, increase seminal concentrations of antioxidants and also improve sperm quality (40) (Level C evidence). In recent years, interest has increased in the role of antioxidants and $\mathrm{B}$ vitamins as modulators of fertility outcome. The antioxidants alpha-tocopherol (Vita$\min \mathrm{A}$ ), ascorbic acid (Vitamin C) and the retinoids (Vitamin A) are potent scavengers of ROS. Deficient vitamin-B concentrations cause elevated homocysteine concentrations and impair the remethylation cycle of phospholipids, proteins, DNA, and RNA. These processes are essential in spermatogenesis. Wong et al. (2002) demonstrated that folic acid (5 mg) and zinc phosphate $(66 \mathrm{mg})$ caused a $74 \%$ increase of total normal sperm count in subfertile men (41) (Level B evidence). Boxmeer et al. (2009) reported for the first time that a low folate concentration in seminal plasma is associated with more sperm DNA damage in fertile men (42). Folate shortage increases DNA fragility due to the misincorporation of uracil instead of thymine. Greco et al. (2005) studied a large cohort of infertile men with $>15 \%$ DNA-fragmented spermatozoa treated with either 1 gram of Vitamin $\mathrm{C}$ and $\mathrm{E}$ daily or placebo for two months, and demonstrated that the percentage of DNA-fragmented spermatozoa was reduced, but with no effects on the sperm parameters (43). The authors further went on to demonstrate that supplementation with vitamins $\mathrm{E}$ and $\mathrm{C}$ significantly increased rates of clinical pregnancy and implantation following ICSI (44) (Level B evidence). Recently, a case series study suggested that an increased intake of antioxidant-rich food or antioxidant supplements (see appendix) by men with high levels of sperm DNA fragmentation or lipid per-

\section{Appendix}

Antioxidant-rich food: $\beta$-carotene (carrots, spinach, tomatoes, papaya, guava, cherries, melons, peaches), vitamin C (guava, kiwi, mango, pineapple, melons, strawberries, berries, tomatoes, broccoli, cabbage, oranges, lemons and other citrus fruits), vitamin E (lettuce, peanuts, almonds, coconut, corn, soy or olive oil; wheat and corn germ; cereals), zinc (asparagus, potatoes, vegetables, eggs, fish). Commercial multivitamins most often contain $\beta$-carotene (5000 IU), vitamin C (60 mg), vitamin E (30 IU), and zinc (15 $\mathrm{mg}$ ). 
oxidation may result in an improvement in gestational outcomes for couples with recurrent embryo losses (45) (Level C evidence).

\section{PREDICTIVE FACTORS AND TECHNIQUES FOR SPERM RETRIEVAL IN NON-OBSTRUCTIVE AZOOSPERMIA}

To date, there are still no absolute preoperative predictive factors for successful sperm retrieval (SR), although the probability seems to depend on the biopsy technique. Microdissection testicular sperm extraction (micro-TESE) has been shown to be more successful in sperm retrieval than a single biopsy or multiple random biopsies $(46,47)$ (Level C evidence). Moreover, micro-TESE seems to have less effect on testicular function because it spares vessels during dissection and removes less tissue than random biopsies (48).

The concept that elevated FSH levels are associated with male sterility has now been challenged. Serum FSH is an indirect reflection of the global spermatogenic function and testis histology. In cases of diffuse maturation arrest (MA), adequate control feedback from germ cells and Sertoli cells exists despite the absence of sperm production (49). Sperm retrieval techniques can obtain sperm from the testicle even in cases of elevated FSH, but their results depend on the retrieval method. Bromage et al. (2007) reported that the probability for sperm retrieval in non obstructive azoospermia (NOA) men with elevated FSH are lower using random biopsy TESE (50), while Ramasamy et al. (2009) demonstrated nearly identical retrieval rates by micro-TESE of $\sim 60 \%$ regardless of FSH levels (51) (Level B evidence).

Testicular histology is considered the best predictor for successful sperm retrieval in NOA. However, even the combination of histology and FSH results provides only a 'fair' accuracy rate of 0.74 (52) (Evidence level B). Nonetheless, Esteves et al. (2006) have shown that SR by micro-TESE were significantly higher in cases of hypospermatogenesis or MA ( $100 \%$ and $75 \%$, respectively) as compared to SCO (32\%) (53), thus highlighting the concept that even the more adverse histological pattern cannot determine if sperm are present elsewhere in the testis.
Recently, the importance of surgical treatment prior to sperm retrieval in NOA men has been highlighted. Inci et al. (2009) reported that treatment of clinical varicoceles prior to SR increased the chance of obtaining testicular sperm using micro-TESE in a group of NOA individuals with clinical varicoceles (54). Retrieval rates were $53 \%$ and $30 \%$ in the treated and untreated men, respectively (odds-ratio [OR]: $2.63 ; 95 \%$ confidence interval $[\mathrm{CI}]$ of $1.05-6.60)$ (Level C evidence).

\section{MICROSURGICAL TREATMENT OF CLINICAL VARICOCELES}

Although several studies demonstrated the beneficial effect of the surgical treatment of clinical varicoceles in infertility $(40,55)$, a recent meta-analysis concluded that treatment of varicocele in men from couples with otherwise unexplained subfertility could not be recommended (56) (Level B evidence). This meta-analysis was challenged by Ficcara et al. (2006), who argued that less than half of the studies in the Cochrane review included patients with abnormal semen analysis and palpable varicocele and demonstrated that its methodology and statistical power was poor, thereby minimizing its significance against varicocele repair (57). The most recent meta-analysis on varicocelectomy unequivocally demonstrated that the chances of obtaining a spontaneous conception were 2.8 times higher in the varicocelectomy group as compared to the group of patients who received either no treatment or medication (58) (Level A evidence). Recently, it has been shown that treatment of clinical varicoceles may also improve the outcomes of assisted reproduction in couples with varicocele-related infertility. Esteves et al. (2010) observed higher pregnancy rates after ICSI in the group of men who underwent microsurgical varicocele repair before ART $(60.3 \%$ versus $45.0 \%$ ), and logistic regression showed that the chance of obtaining a clinical pregnancy was increased by $69 \%$ if the varicocele had been treated before ICSI (OR: 1.69, 95\% CI 1.00-2.84). Also, the chance of having a miscarriage after ICSI was significantly reduced by 2.3 times if the varicocele had been treated (OR: $0.433 ; 95 \%$ CI $0.22-0.83 ; \mathrm{P}=0.01$ ) (59). (Level C evidence). 
To date varicoceles are treated using different techniques. A recent systematic review including 4,473 individuals concluded that open microsurgical inguinal or sub-inguinal varicocelectomy techniques resulted in higher spontaneous pregnancy rates with fewer recurrences and postoperative complications than laparoscopic, radiologic embolization and macroscopic inguinal or retroperitoneal varicocelectomy (60) (Level A evidence).

\section{CONCLUSIONS}

The entire duration of the spermatogenic cycle is shorter ( $\sim 60$ days) than the previously suspected 70 to 80 -day period. About $10 \%$ of the infertile male population previously misdiagnosed as idiopathic have de novo Yq microdeletions, and the presence or absence of sperm (ejaculated or retrieved) vary depending on the specific deletion. Although no treatment exists, ICSI may be effective but the male offspring will inherit the same deletion as their father. In $\sim 50 \%$ of non-mosaic KS azoospermic men testicular sperm are found by micro-TESE. Children born after ICSI using testicular sperm from KS men have normal karyotype because the minor foci of germ cells into the seminiferous tubuli are euploid. Sperm quality declines with paternal age beginning as early as age 35 , and it may explain certain cases of male infertility, recurrent miscarriages and the occurrence of autosomal dominant, single gene disorders in offspring. Abnormalities in the male genome characterized by damaged sperm DNA may be indicative of male subfertility regardless of normal routine semen parameters. DNA integrity testing is now clinically available and results may predict reproductive outcomes. Oxidative stress is associated with sperm quality and infertility. Therapeutic measures to decrease OS, including lifestyle modifications, varicocelectomy in selected cases and the use of vitamins/antioxidants, show promising results. In the subset of men with NOA, FSH levels are not predictive of SR or sterility. Micro-TESE yields the best SR rates in NOA; success may be optimized by surgical treatment of clinical varicoceles or by medical therapy in non-mosaic KS men. Microsurgical varicocelectomy is associated with lower recurrence and complications. Spontaneous and assisted-conception conception may be increased after repair of clinical varicocele. We hope that our review will provide a better understanding of evolving concepts in the field of male infertility to urologists and male infertility specialists. This increased knowledge will no doubt aid in the better management and treatment of the infertile male.

\section{ACKNOWLEDGEMENTS}

Extracted from a Roundtable Syllabus "New Concepts in Male Infertility", presented by the author (SCE) at the 2009 American Society for Reproductive Medicine Annual Meeting, Atlanta, Georgia, USA.

\section{CONFLICT OF INTEREST}

None declared.

\section{REFERENCES}

1. Vital and Health Statistics, series 23, no. 26, CDC, 2002. http://www.cdc.gov

2. Centre for evidence-based medicine: Oxford Centre for Evidence-based Medicine - Levels of Evidence, March 2009. http://www.cebm.net/index.aspx?o=1025

3. Clermont Y: Kinetics of spermatogenesis in mammals: seminiferous epithelium cycle and spermatogonial renewal. Physiol Rev. 1972; 52: 198-236.

4. Misell LM, Holochwost D, Boban D, Santi N, Shefi N, Hellerstein MK, Turek PJ: A stable isotope-mass spectrometric method for measuring human spermatogenesis kinetics in vivo. J Urol. 2006; 175: 242-6.

5. Nathanson KL, Kanetsky PA, Hawes R, Vaughn DJ, Letrero R, Tucker $\mathrm{K}$ et al: The $\mathrm{Y}$ deletion $\mathrm{gr} / \mathrm{gr}$ and susceptibility to testicular germ cell tumor. Am J Hum Genet. 2005; 77: 1034-43.

6. Simoni M: Clinical consequences of microdeletions of the $Y$ chromosome: the extended Münster experience. RBM online 2008; 16: 289-30.

7. Repping S, Skaletsky H, Lange J, Silber S, Van Der Veen F, Oates RD, Page DC, Rozen S: Recombination between palindromes P5 and P1 on the human Y chromosome causes massive deletions and spermatogenic failure. Am J Hum Genet. 2002; 71: 906-22. 
8. Shefi S, Turek PJ: Definition and current evaluation of subfertile men. Int Braz J Urol. 2006; 32: 385-97.

9. Sun C, Skaletsky H, Rozen S, Gromoll J, Nieschlag E, Oates R, Page DC: Deletion of azoospermia factor a (AZFa) region of human Y chromosome caused by recombination between HERV15 proviruses. Hum Mol Genet: 2000; 9: 2291-6.

10. Kamp C, Huellen K, Fernandes S, Sousa M, Schlegel PN, Mielnik A, Kleiman S, Yavetz H, Krause W, Küpker W, Johannisson R, Schulze W, Weidner W, Barros A, Vogt PH: High deletion frequency of the complete AZFa sequence in men with Sertoli-cell-only syndrome. Mol Hum Reprod. 2001; 7: 987-94.

11. Hopps CV, Mielnik A, Goldstein M, Palermo GD, Rosenwaks Z, Schlegel PN: Detection of sperm in men with Y chromosome microdeletions of the AZFa, $\mathrm{AZFb}$ and AZFc regions. Hum Reprod. 2003; 18: 1660-5.

12. Saut N, Terriou P, Navarro A, Levy N, Mitchell MJ: The human Y chromosome genes BPY2, CDY1 and DAZ are not essential for sustained fertility. Mol Hum Reprod. 2000; 6: 789-93.

13. Schiff JD, Palermo GD, Veeck LL, Goldstein M, Rosenwaks Z, Schlegel PN: Success of testicular sperm injection and intracytoplasmic sperm injection in men with Klinefelter syndrome. J Clin Endocrinol Metab. 2005; 90: 6263-7.

14. Staessen C, Tournaye H, Van Assche E, Michiels A, Van Landuyt L, Devroey P, Liebaers I, Van Steirteghem A: PGD in 47, XXY Klinefelter's syndrome patients. Hum Reprod Update. 2003; 9: 319-30.

15. Sciurano RB, Luna Hisano CV, Rahn MI, Brugo Olmedo S, Rey Valzacchi G, Coco R, Solari AJ: Focal spermatogenesis originates in euploid germ cells in classical Klinefelter patients. Hum Reprod. 2009; 24: 2353-60.

16. Ramasamy R, Ricci JA, Palermo GD, Gosden LV, Rosenwaks Z, Schlegel PN: Successful fertility treatment for Klinefelter's syndrome. J Urol. 2009; 182: 1108-13.

17. Johnson L, Petty CS, Porter JC, Neaves WB: Germ cell degeneration during postprophase of meiosis and serum concentrations of gonadotropins in young adult and older adult men. Biol Reprod. 1984; 31: 779-84.

18. Wyrobek AJ, Aardema M, Eichenlaub-Ritter U, Ferguson L, Marchetti F: Mechanisms and targets involved in maternal and paternal age effects on numerical aneuploidy. Environ Mol Mutagen. 1996; 28: 254-64.

19. Moskovtsev SI, Willis J, Mullen JB: Age-related decline in sperm deoxyribonucleic acid integrity in patients evaluated for male infertility. Fertil Steril. 2006; 85: 496-9.

20. Siddighi S, Chan CA, Patton WC, Jacobson JD, Chan PJ: Male age and sperm necrosis in assisted reproductive technologies. Urol Int. 2007; 9: 231-4.

21. Plastira K, Msaouel P, Angelopoulou R, Zanioti K, Plastiras A, Pothos A, Bolaris S, Paparisteidis N, Mantas D: The effects of age on DNA fragmentation, chromatin packaging and conventional semen parameters in spermatozoa of oligoasthenoteratozoospermic patients. J Assist Reprod Genet. 2007; 24: 437-43.

22. Agarwal A, Said TM: Role of sperm chromatin abnormalities and DNA damage in male infertility. Hum Reprod Update. 2003; 9: 331-45.

23. Erenpreiss J, Spano M, Erenpreiss J, Bungum M, Giwercman A: Sperm chromatin structure and male fertility: biological and clinical aspects. Asian J Androl. 2006; 8: 11-29.

24. Bungum M, Humaidan P, Spano M, Jepson K, Bungum L, Giwercman A: The predictive value of sperm chromatin structure assay (SCSA) parameters for the outcome of intrauterine insemination, IVF and ICSI. Hum Reprod. 2004; 19: 1401-8.

25. Duran EH, Morshedi M, Taylor S, Oehninger S: Sperm DNA quality predicts intrauterine insemination outcome: a prospective cohort study. Hum Reprod. 2002; 17: 3122-8.

26. Seli E, Gardner DK, Schoolcraft WB, Moffatt O, Sakkas D: Extent of nuclear DNA damage in ejaculated spermatozoa impacts on blastocyst development after in vitro fertilization. Fertil Steril. 2004; 82: 378-83.

27. Larson-Cook KL, Brannian JD, Hansen KA, Kasperson KM, Aamold ET, Evenson DP: Relationship between the outcomes of assisted reproductive techniques and sperm DNA fragmentation as measured by the sperm chromatin structure assay. Fertil Steril. 2003; 80: 895-902.

28. Collins JA, Barnhart KT, Schlegel PN: Do sperm DNA integrity tests predict pregnancy with in vitro fertilization? Fertil Steril. 2008; 89: 823-31.

29. Carrell DT, Liu L, Peterson CM, Jones KP, Hatasaka HH, Erickson L, Campbell B.: Sperm DNA fragmentation is increased in couples with unexplained recurrent pregnancy loss. Arch Androl. 2003; 49: 49-55.

30. Evenson DP, Jost LK, Marshall D, Zinaman MJ, Clegg E, Purvis K, de Angelis P, Claussen OP: Utility of the sperm chromatin structure assay as a diagnostic and prognostic tool in the human fertility clinic. Hum Reprod. 1999; 14: 1039-49.

31. Aitken RJ, Krausz C: Oxidative stress, DNA damage and the Y chromosome. Reproduction. 2001; 122: 497-506. 
32. Hansen M, Kurinczuk JJ, Bower C, Webb S: The risk of major birth defects after intracytoplasmic sperm injection and in vitro fertilization. N Engl J Med. 2002; 346: 725-30.

33. Kefer JC, Agarwal A, Sabanegh E: Role of antioxidants in the treatment of male infertility. International J Urol. 2009; 16: 449-57.

34. Auger J, Eustache F, Andersen AG, Irvine DS, Jørgensen N, Skakkebaek NE, Suominen J, Toppari J, Vierula M, Jouannet P: Sperm morphological defects related to environment, lifestyle and medical history of 1001 male partners of pregnant women from four European cities. Hum Reprod. 2001; 16: 2710-7.

35. Kasahara E, Sato EF, Miyoshi M, Konaka R, Hiramoto K, Sasaki J, Tokuda M, Nakano Y, Inoue M: Role of oxidative stress in germ cell apoptosis induced by di(2-ethylhexyl)phthalate. Biochem J. 2002; 365: $849-56$.

36. Gennart JP, Buchet JP, Roels H, Ghyselen P, Cuelemans E, Lauerys R: Fertility of male workers exposed to cadmium, lead or manganese. Am J Epidemiol. 1992; 135: 1208-19.

37. Gonzalez-Flecha B: Oxidant mechanisms in response to ambient air particles. Mol Aspects Med. 2004; 25: 169-82.

38. Vine MF: Smoking and male reproduction: A review. Int J Androl.1996; 19: 323-7.

39. Agarwal A, Makker K, Sharma R: Clinical relevance of oxidative stress in male factor infertility: an update. Am J Reprod Immunol. 2008; 59: 2-11.

40. Zini A, Blumenfeld A, Libman J, Willis J: Beneficial effect of microsurgical varicocelectomy on human sperm DNA integrity. Hum Reprod. 2005; 20: 1018-21.

41. Wong WY, Merkus HM, Thomas CM, Menkveld R, Zielhuis GA, Steegers-Theunissen RP: Effects of folic acid and zinc sulfate on male factor subfertility: a double-blind, randomized, placebo-controlled trial. Fertil Steril. 2002; 77: 491-8.

42. Boxmeer JC, Smit M, Utomo E, Romijn JC, Eijkemans MJ, Lindemans J, Laven JS, Macklon NS, Steegers EA, Steegers-Theunissen RP: Low folate in seminal plasma is associated with increased sperm DNA damage. Fertil Steril 2009; 92: 548-56.

43. Greco E, Iacobelli M, Rienzi L, Ubaldi F, Ferrero S, Tesarik J: Reduction of the incidence of sperm DNA fragmentation by oral antioxidant treatment. J. Androl. 2005; 26: 349-53.

44. Greco E, Romano S, Iacobelli M, Ferrero S, Baroni E, Minasi MG, Ubaldi F, Rienzi L, Tesarik J: ICSI in cases of sperm DNA damage: Beneficial effect of oral antioxidant treatment. Hum. Reprod. 2005; 20: 2590-4.
45. Gil-Villa AM, Cardona-Maya W, Agarwal A, Sharma $\mathrm{R}$, Cadavid A: Role of male factor in early recurrent embryo loss: do antioxidants have any effect? Fertil Steril. 2009; 92: 565-71.

46. Schlegel PN: Testicular sperm extraction: Microdissection improves sperm yield with minimal tissue excision. Hum Reprod 1999; 14: 131-5.

47. Okada H, Dobashi M, Yamazaki T, Hara I, Fujisawa M, Arakawa S, Kamidono S: Conventional versus microdissection testicular sperm extraction for nonobstructive azoospermia. J Urol. 2002; 168: 1063-7.

48. Ramasamy R, Yagan N, Schlegel PN: Structural and functional changes to the testis after conventional versus microdissection testicular sperm extraction. Urology. 2005; 65: 1190-4.

49. Hung AJ, King P, Schlegel PN: Uniform testicular maturation arrest: a unique subset of men with nonobstructive azoospermia. J Urol. 2007; 178: 608-12.

50. Bromage SJ, Falconer DA, Lieberman BA, Sangar V, Payne SR: Sperm retrieval rates in subgroups of primary azoospermic males. Eur Urol. 2007; 51: 534-9.

51. Ramasamy R, Lin K, Gosden LV, Rosenwaks Z, Palermo GD, Schlegel PN: High serum FSH levels in men with nonobstructive azoospermia does not affect success of microdissection testicular sperm extraction. Fertil Steril. 2009; 92: 590-3.

52. Tournaye H, Verheyen G, Nagy P, Ubaldi F, Goossens A, Silber S, Van Steirteghem AC, Devroey P: Are there any predictive factors for successful testicular sperm recovery in azoospermic patients? Hum Reprod. 1997; 12: 80-6.

53. Esteves SC, Verza Jr S, Gomes AP: Successful retrieval of testicular spermatozoa by microdissection (microTESE) in nonobstructive azoospermia is related to testicular histology. Fertil Steril 2006;86: Suppl., 354.

54. Inci K, Hascicek M, Kara O, Dikmen AV, Gürgan T, Ergen A. Sperm retrieval and intracytoplasmic sperm injection in men with nonobstructive azoospermia, and treated and untreated varicocele. J Urol. 2009; 182: 1500-5.

55. Esteves SC, Glina S: Recovery of spermatogenesis after microsurgical subinguinal varicocele repair in azoospermic men based on testicular histology. Int Braz J Urol. 2005; 31: 541-8.

56. Evers JLH, Collins JA: Assessment of efficacy of varicocele repair for male subfertility: A systematic review. Lancet. 2003; 361: 1849-52.

57. Ficcara V, Cerruto MA, Liguori G, Mazzoni G, Minucci S, Tracia A, Gentile V: Treatment of varicocele in subfertile men: The Cochrane review - a contrary opinion. Eur Urol. 2006; 49: 258-63. 
58. Marmar JL, Agarwal A, Prabaskan S, Agarwal R, Short RA, Benoff S, Thomas AJ Jr: Reassessing the value of varicocelectomy as a treatment for male subfertility with a new meta-analysis. Fertil Steril. 2007; 88: 639-48.

59. Esteves SC, Oliveira FV, Bertolla RP: Clinical outcomes of intracytoplasmic sperm injection in infertile men with treated and untreated clinical varicocele. J Urol. 2010; 184: 1442-46.

60. Cayan S, Shavakhabov S, Kadioglu A. Treatment of palpable varicocele review in infertile men: a metaanalysis to define the best technique. J Androl. 2009; 30: 33-40.

\section{Correspondence Address:}

Dr. Sandro Esteves

ANDROFERT - Center for Male Reproduction

Av. Dr. Heitor Penteado, 1464

13075-460, Campinas, São Paulo, BRAZIL

Fax: + 5519 3294-6992

E-mail: s.esteves@androfert.com.br 